\title{
Oxygen vacancy doping of hematite analyzed by electrical conductivity and thermoelectric power measurements
}

\author{
Jan Mock, ${ }^{1}$ Benjamin Klingebiel, ${ }^{1}$ Florian Köhler, ${ }^{1}$ Maurice Nuys, ${ }^{1}$ Jan Flohre, ${ }^{1}$ Stefan Muthmann, ${ }^{1}$ \\ Thomas Kirchartz, ${ }^{1,2}$ and Reinhard Carius ${ }^{1}$ \\ ${ }^{1}$ IEK5-Photovoltaik, Forschungszentrum Jülich, 52425 Jülich, Germany \\ ${ }^{2}$ Faculty of Engineering and CENIDE, University of Duisburg-Essen, Carl-Benz-Strasse 199, 47057 Duisburg, Germany
}

(Received 19 July 2017; published 22 November 2017)

\begin{abstract}
Hematite $\left(\alpha-\mathrm{Fe}_{2} \mathrm{O}_{3}\right)$ is known for poor electronic transport properties, which are the main drawback of this material for optoelectronic applications. In this study, we investigate the concept of enhancing electrical conductivity by the introduction of oxygen vacancies during temperature treatment under low oxygen partial pressure. We demonstrate the possibility of tuning the conductivity continuously by more than five orders of magnitude during stepwise annealing in a moderate temperature range between 300 and $620 \mathrm{~K}$. With thermoelectric power measurements, we are able to attribute the improvement of the electrical conductivity to an enhanced charge-carrier density by more than three orders of magnitude. We compare the oxygen vacancy doping of hematite thin films with hematite nanoparticle layers. Thereby we show that the dominant potential barrier that limits charge transport is either due to grain boundaries in hematite thin films or due to potential barriers that occur at the contact area between the nanoparticles, rather than the potential barrier within the small polaron hopping model, which is usually applied for hematite. Furthermore, we discuss the transition from oxygen-deficient hematite $\alpha-\mathrm{Fe}_{2} \mathrm{O}_{3-x}$ towards the magnetite $\mathrm{Fe}_{3} \mathrm{O}_{4}$ phase of iron oxide at high density of vacancies.
\end{abstract}

DOI: 10.1103/PhysRevMaterials.1.065407

\section{INTRODUCTION}

Iron(III) oxide, $\alpha-\mathrm{Fe}_{2} \mathrm{O}_{3}$, also known as hematite, is considered a promising candidate as photoanode material for photoelectrochemical (PEC) solar water-splitting devices [1-4] as well as a candidate for gas-sensors [5-8], lithium ion batteries [9], and water treatment [10,11]. Consisting of abundant and nontoxic elements, $\alpha-\mathrm{Fe}_{2} \mathrm{O}_{3}$ has been studied as a potential candidate for PEC devices due to its sufficient light absorption, chemical stability, and suitable band gap $[1,2,12-14]$. In theory, the optical band gap of $2.2 \mathrm{eV}$ of $\alpha-\mathrm{Fe}_{2} \mathrm{O}_{3}$ has the potential to convert up to $12.9 \%$ of the sun's energy into hydrogen [15]. This efficiency is far from being reached by state-of-the-art devices, which is mainly due to ultrafast charge-carrier recombination, which results in very short diffusion length of only a few nanometers $[1,16]$. Thus, improvement of the electrical transport properties is mandatory for the future application of $\alpha-\mathrm{Fe}_{2} \mathrm{O}_{3}$ in PEC devices.

The study of the electrical transport properties of hematite has a long history with respect to material purity, impurity doping, as well as off-stoichiometric (oxygen vacancy) effects. So far most of the work has been focused on high-temperature treatments $(>1000 \mathrm{~K})$ and measurements above $600 \mathrm{~K}$ [1737]. Within the past years, a series of studies was performed that provided evidence for a relation between the preparation of $\alpha-\mathrm{Fe}_{2} \mathrm{O}_{3}$ in oxygen-deficient environments and enhanced electrical transport properties, which yields a higher PEC performance [38-48]. For instance, the concept of oxygen vacancy doping was applied during the deposition of hematite and revealed a higher concentration of $\mathrm{Fe}^{2+}$ sites, which act as shallow donors and therefore increase the chargecarrier density of hematite [38]. But, the introduction of too many oxygen vacancies also causes a reduction of the PEC performance $[40,45]$, which is explained by a partial transition into the magnetite $\left(\mathrm{Fe}_{3} \mathrm{O}_{4}\right)$ phase of iron oxide for temperatures above $623 \mathrm{~K}$ [45].
Thus, based on the evidence in the literature so far, we can conclude that the charge-carrier density rises by introducing oxygen vacancies $\left(\alpha-\mathrm{Fe}_{2} \mathrm{O}_{3-x}\right.$ with rising $x$ ) for annealing temperatures above $543 \mathrm{~K}$ at "ultrahigh-vacuum conditions" [45] and for annealing above $683 \mathrm{~K}$ at $10^{-5}$ mbar oxygen partial pressure [18]. But it is not clear what happens for temperatures below $543 \mathrm{~K}$. Therefore, we study the temperature-dependent electrical conductivity and thermoelectric power of $\alpha-\mathrm{Fe}_{2} \mathrm{O}_{3}$ to determine how annealing under vacuum conditions affects the charge-carrier density of oxygen-deficient hematite. We enhance the electrical conductivity of hematite nanoparticle layers as well as thin films by more than five orders of magnitude and demonstrate the continuous tunability of the transport properties by stepwise annealing in the moderate temperature range between 300 and $620 \mathrm{~K}$ at a vacuum base pressure on the order of $10^{-6}$ mbar. We discuss the introduction of oxygen vacancies in $\alpha-\mathrm{Fe}_{2} \mathrm{O}_{3-x}$ prior to the transition into the magnetite $\left(\mathrm{Fe}_{3} \mathrm{O}_{4}\right)$ phase of iron oxide, which occurs already at $620 \mathrm{~K}$ in drastic contradiction to the expected phase-change transition temperature of $1000 \mathrm{~K}$ at an oxygen partial pressure of $10^{-7}$ mbar [49].

\section{METHODS}

\section{A. Sample preparation (nanoparticle samples)}

Hematite nanoparticles are provided by the Institute of Interactive Materials Research DWI an der RWTH Aachen e.V. The nanoparticles are prepared according to the synthesis reported elsewhere [50,51] and are available as a dispersion in water with a concentration of about $1.5 \mathrm{wt} \%$. Structural and optoelectronic properties of these particles are already reported by our group [52]. The diameter of the nanoparticle is $60 \pm 10 \mathrm{~nm}$. For nanoparticle layer preparation, $8 \times 15 \mathrm{~mm}^{2}$ quartz glass substrates were cleaned for $15 \mathrm{~min}$ in an ultrasonic bath with ethanol. Afterwards, the wettability of the glass 
substrate was enhanced by an oxygen plasma treatment for about 9 min in 0.3 mbar oxygen atmosphere (Diener electronic $\mathrm{GmbH}+\mathrm{Co}$. KG, Modell Zepto, 13.56 MHz, 50 W). For electrical conductivity as well as for thermoelectric power measurements, coplanar silver contact stripes with a thickness of $100 \mathrm{~nm}$ were deposited on the quartz substrates by vacuum evaporation. Afterwards, the hematite nanoparticles were deposited by spin coating. The best nanoparticle layer homogeneity was achieved by multiple spin coating: five times $30-\mu \mathrm{l}$ dispersion at $30 \mathrm{rps}$. For scanning electron microscopy (SEM) imaging of the untreated nanoparticle, cleaned $\mathrm{ZnO}$ substrates were used. The nanoparticle layer thickness was determined to be $500 \pm 100 \mathrm{~nm}$ using a profilometer.

\section{B. Sample preparation (thin films)}

Hematite thin films were prepared by plasma-enhanced chemical vapor deposition (PECVD) as reported elsewhere $[53,54]$. Three different deposition temperatures were used (room temperature, $200^{\circ} \mathrm{C}$, and $400^{\circ} \mathrm{C}$ ) at an oxygen flow of $30 \mathrm{sccm}$. Afterwards, the samples were annealed at $550{ }^{\circ} \mathrm{C}$ for $3 \mathrm{~h}$ under a synthetic air environment. The samples were cut into about $10 \times 15 \mathrm{~mm}^{2}$ pieces and coplanar silver contacts were evaporated similar to the nanoparticle sample.

\section{Electrical conductivity and thermoelectric power}

The electrical conductivity as well as the thermoelectric power measurements are based on Ref. [55]. The setup consists of a vacuum chamber with a gas inlet for different atmospheres (e.g., synthetic air, nitrogen). Under vacuum conditions, atmospheres between $3 \times 10^{-7}$ and $1 \times 10^{-6}$ mbar can be achieved. The sample is thermally contacted with silver glue on a sapphire glass holder, which is connected to two independent heaters (Fig. S1 [57]). For electrical contact as well as for determination of the sample temperature, two $50-\mu \mathrm{m}$ thin type-E (NiCr/CuNiMn) thermocouples are glued on the surface of the investigated material. Usually, two 8-mm-wide coplanar metal (Ag) contact stripes with a distance of $4 \mathrm{~mm}$ are evaporated on the samples. Considering the contact geometry and the layer thickness, the electrical conductivity is determined by applying $100 \mathrm{~V}$ to the sample and measuring the resulting current by a Keithley617 electrometer. The thermovoltage is determined by applying a temperature gradient of $60 \mathrm{~K}$ at the heaters, which results in a temperature gradient of about $15 \mathrm{~K}$ between the metal contact stripes on the sample. To determine the Seebeck coefficient $S(T)$ (thermoelectric power) the temperature gradient is applied successively with a positive and negative sign around the average sample temperature $T$. The resulting thermovoltages are fitted linearly to determine the thermoelectric power. The charge-carrier density is calculated by the thermoelectric power. Therefore, a temperature-dependent effective density of states $N_{\mathrm{C}}(T)$,

$$
N_{\mathrm{C}}(T)=2\left(\frac{2 \pi m_{\mathrm{eff}} k T}{h^{2}}\right)^{3 / 2},
$$

where $k$ is the Boltzmann constant and $h$ the Planck constant, was assumed for $n$-type $\mathrm{Fe}_{2} \mathrm{O}_{3}$ to be $5 \times 10^{15} \mathrm{~T}^{3 / 2} \mathrm{~cm}^{-3}$, which corresponds to an effective electron mass that is set to one electron mass $\left(m_{\mathrm{eff}}=1 m_{\mathrm{e}}\right)$. It is worth noting that this assumed effective electron mass is too small for charge transport via small polaron hopping [28]. Furthermore, ionized defect scattering was assumed as the dominant scattering mechanism for the charge-carrier density calculation, which leads for a nondegenerated semiconductor to the expression of the thermoelectric power:

$$
S(T)=-\frac{k}{e}\left(\frac{4 F_{3}\left(\mu^{*}(T)\right)}{3 F_{2}\left(\mu^{*}(T)\right)}-\left(\mu^{*}(T)\right)\right),
$$

where $\mu^{*}(T)=\frac{E_{\mathrm{F}}-E_{\mathrm{C}}}{k T}$ is the reduced Fermi energy, $e$ is the elementary charge, and $F_{\mathrm{x}}$ is the Fermi-Dirac integral [56]. We performed the following calculation of the charge-carrier density while assuming phonon scattering to be the dominant scattering mechanism and we provide these results in the Supplemental Material [57]. To calculate the charge-carrier density, (2) gets solved for $\mu^{*}(T)$ and inserted into

$$
n(T)=N_{\mathrm{C}}(T) F_{1 / 2}\left(\mu^{*}(T)\right)
$$

with the effective density of states as mentioned above. By including the electrical conductivity, the charge-carrier mobility can be calculated by the well-known dependency

$$
\sigma(T)=e n(T) \mu(T) .
$$

By this, the assumed effective density of states affects $n$ and $\mu$ linearly, which is again affected by the effective electron mass. As an example, for a twofold-higher effective electron mass the calculated charge-carrier density would be $2^{3 / 2}$ times smaller and the mobility $2^{2 / 3}$ times higher. Therefore, the determination of the absolute values by the thermoelectric power of $n$ and $\mu$ is based on the knowledge of the dominant scattering mechanism and the effective electron mass. But, relative changes of $n$ and $\mu$ remain to be meaningful.

\section{Raman spectroscopy}

Raman measurements under ambient conditions were performed with a cooled silicon CCD adapted to a single grating monochromator. The excitation was done by a 532-nm semiconductor laser (Coherent Saphire).

\section{E. Photothermal deflection spectroscopy}

Hematite nanoparticles were spin coated on a quartz glass substrate in a glove-box environment as described before. Photothermal deflection spectroscopy (PDS) was used as a highly sensitive technique to obtain the absorptance of hematite nanoparticle layers in a dynamic range of several orders of magnitude. A detailed description of this method can be found elsewhere [58,59]. The sample is measured in a cuvette filled with a $\mathrm{CCl}_{4}$ solution, which is chemically inert and exhibits a temperature-dependent refractive index. A halogen lamp $(100 \mathrm{~W})$ in combination with a spectrometer (270 M from Horiba Jobin Yvon) illuminates the sample with monochromatic light in transverse mode. Any photon energy absorbed by the sample will eventually be converted into heat, which is released to the surrounding media. A probe beam from a diode laser $(650 \mathrm{~nm})$, adjusted in parallel to the sample surface, will be deflected due to the gradient in the refractive 


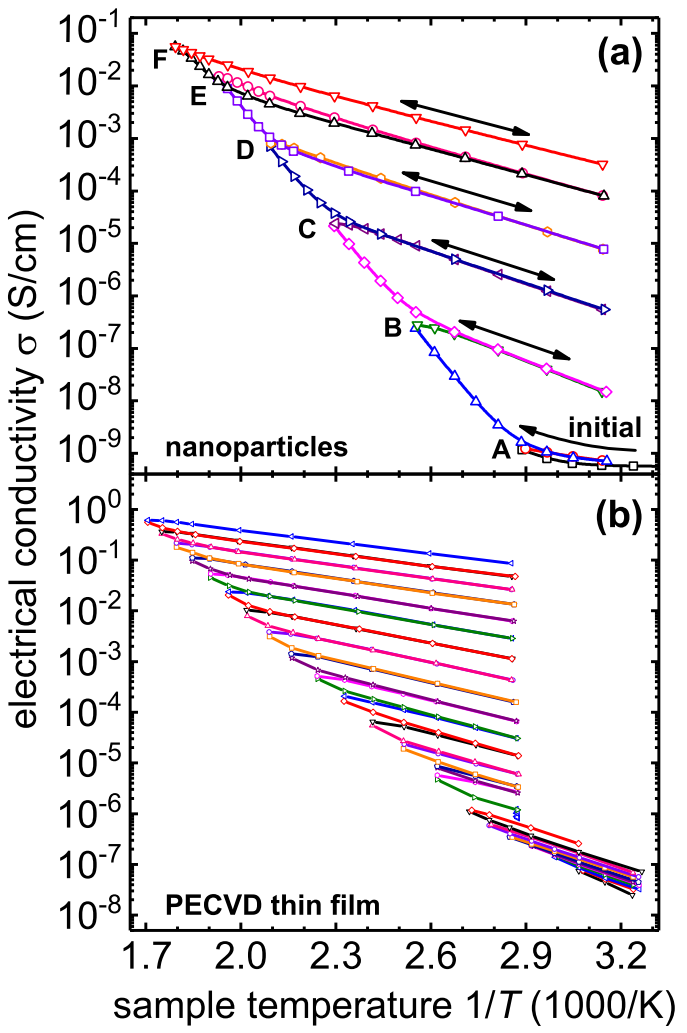

FIG. 1. Electrical conductivity of hematite as a function of the reciprocal temperature during measurement. (a) A representative nanoparticle layer sample. The maximum measurement temperature ( $T_{\max }$ ) was increased successively (A to F). After each $T_{\max }$, the sample was cooled down to $317 \mathrm{~K}$ (as indicated by the arrows). (b) Thin-film sample prepared by PECVD at a deposition temperature of $200{ }^{\circ} \mathrm{C}$. The annealing routine is similar to the nanoparticle sample, whereas the $T_{\max }$ steps were performed in smaller increments. The duration to acquire one data point is between 1 and $2 \mathrm{~h}$. The maximum sample temperature (e.g., A to F) was kept for about $2 \mathrm{~h}$ before the sample was cooled down.

index of the chemical. Finally, the deflection angle, monitored by a silicon four-quadrant diode, is directly proportional to the power of the absorbed light. After the PDS measurements were taken, the sample was annealed with stepwise increased annealing temperatures in an inert glove-box environment on a hot plate, where the sample temperature was determined with a glued-on 50- $\mu \mathrm{m}$ type-E thermocouple. The sample was handled exclusively under inert conditions in between the measurement and the annealing.

\section{RESULTS}

The following results of electrical conductivity and thermoelectric power measurements have been performed at a vacuum base pressure of $1 \times 10^{-6}$ to $3 \times 10^{-7}$ mbar. Figure 1 (a) shows an Arrhenius plot of the electrical conductivity $\sigma$ of about ten monolayers (about $500 \mathrm{~nm}$ ) of spherical hematite nanoparticles (diameter about $60 \pm 10 \mathrm{~nm}$; see Fig. 7). Initially, the electrical conductivity of the nanoparticle-layer sample was measured for temperatures starting at room temperature up to $346 \mathrm{~K}$ (labeled by A) and down to $317 \mathrm{~K}$. Afterwards, we repeated the measurement up to a maximum sample temperature $T_{\max }$ of $391 \mathrm{~K}$ (labeled by B) and cooled down the sample again, as indicated by the arrow. So, we performed electrical conductivity measurements in parallel to temperature annealing under vacuum conditions. This annealing routine was repeated several times with successively increasing maximum sample temperatures ( $\mathrm{C}$ to $\mathrm{F}$ ). The initial electrical resistance of the sample was higher than $25 \mathrm{~T} \Omega$, which is the experimental limit of the setup $\left(\sigma_{\text {limit }} 6 \times 10^{-10} \mathrm{~S} / \mathrm{cm}\right.$ at a layer thickness of $500 \mathrm{~nm}$ ). By heating the sample to $391 \mathrm{~K}$ (B), the electrical conductivity increased to $2.7 \times 10^{-7} \mathrm{~S} / \mathrm{cm}$. After reducing the temperature to $317 \mathrm{~K}$, the electrical conductivity remained enhanced at $1.5 \times 10^{-8} \mathrm{~S} / \mathrm{cm}$ as compared to the initial state. After we repeated the annealing routine six times with $T_{\max }$ up to $557 \mathrm{~K}$ (label F) the electrical conductivity was enhanced by more than six orders of magnitudes from about $10^{-10}$ up to $10^{-4} \mathrm{~S} / \mathrm{cm}$ at $317 \mathrm{~K}$. A comparable annealing procedure with more cycles was also performed with $\alpha-\mathrm{Fe}_{2} \mathrm{O}_{3}$ thin films, prepared by PECVD, which is shown in Fig. 1(b). In both cases, the stepwise annealing forms "metastable conductivity levels" for each maximum annealing temperature $T_{\max }$.

The electrical conductivity of the samples in the "metastable" regime is thermally activated; i.e.,

$$
\sigma(T) \propto \exp \left(-\frac{E_{\mathrm{A}}}{k T}\right)
$$

describes the activation energy $E_{\mathrm{A}}$ of the electrical conductivity. We calculated $E_{\mathrm{A}}$ for each metastable conductivity level. Figure 2 shows the activation energy of six investigated nanoparticle samples (depicted in orange) as a function of $T_{\max }$ as well as the thin-film samples with deposition temperatures of $20^{\circ} \mathrm{C}, 200^{\circ} \mathrm{C}$, and $400^{\circ} \mathrm{C}$ (depicted in black, red, and blue, respectively). For the nanoparticle samples, the activation energy decreases linearly from $0.53 \mathrm{eV}$ for a maximum annealing temperature of $350 \mathrm{~K}$ to $0.3 \mathrm{eV}$ for samples that are annealed up to $600 \mathrm{~K}$. In the same annealing temperature range,

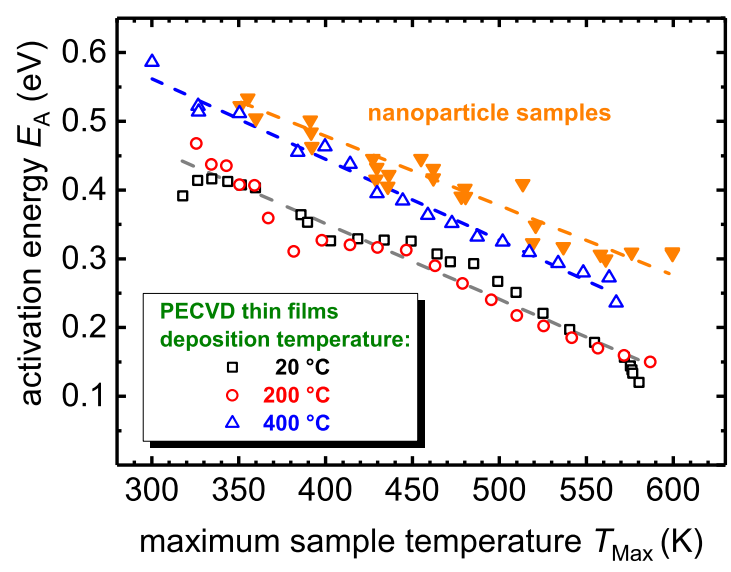

FIG. 2. Activation energy $E_{\mathrm{A}}$ of the temperature-dependent electrical conductivity (from Fig. 1) as a function of the maximum sample temperature $\left(T_{\max }\right)$. Depicted are six investigated nanoparticle samples (orange) and three thin-film samples, which were prepared by PECVD at deposition temperatures of $20^{\circ} \mathrm{C}, 200^{\circ} \mathrm{C}$, and $400^{\circ} \mathrm{C}$ (depicted in black, red, and blue, respectively). 
a comparable decrease of roughly $0.2 \mathrm{eV}$ was observed for the PECVD samples. The activation energy for thin-film samples deposited at $20^{\circ} \mathrm{C}$ and $200^{\circ} \mathrm{C}$ is $0.13 \mathrm{eV}$ lower compared to the nanoparticle samples (as indicated by the gray dashed line), whereas $E_{\mathrm{A}}$ values of the PECVD sample prepared at $400^{\circ} \mathrm{C}$ are close to those of the nanoparticle samples. We discuss the activation energy in detail later.

To investigate the influence of the atmospheric environment on the electrical conductivity, the annealing and measurement sequence, as described before (referred to as a "run" in the following), was performed eight times with alternating atmospheres between vacuum conditions and 500 mbar dry synthetic air $\left(80 \% \mathrm{~N}_{2}, 20 \% \mathrm{O}_{2}\right)$. For a better clearness of display, Fig. 3(a) shows only four of those eight runs. The complete data set is shown in Fig. S2 of the Supplemental Material [57]. The first run in vacuum was performed with very small temperature increments and reveals the onset of enhanced conductivities for temperatures above $337 \mathrm{~K}$ [Fig. S2(b)]. Afterwards, an annealing up to $590 \mathrm{~K}$ in synthetic air was performed (second run). The Arrhenius plot in Fig. 3(a) starts at the third run under vacuum conditions (solid blue triangles). The conductivity increases continuously with each annealing step and remains enhanced up to $8.3 \times 10^{-6} \mathrm{~S} / \mathrm{cm}$ (at $320 \mathrm{~K}$ ) after annealing up to $560 \mathrm{~K}$. After the setup was filled with synthetic air at room temperature, the electrical conductivity dropped within less than $20 \mathrm{~min}$ by more than three orders of magnitude down to $5.7 \times 10^{-9} \mathrm{~S} / \mathrm{cm}($ at $320 \mathrm{~K})$, as indicated by the orange arrow, and further decreased within the next $2 \mathrm{~h}$ to $3.7 \times 10^{-9} \mathrm{~S} / \mathrm{cm}$ (at $320 \mathrm{~K}$ ). The stepwise annealing up to a maximum temperature of $560 \mathrm{~K}$ under synthetic air (fourth run, open red triangles) reduced the electrical conductivity successively to about $1 \times 10^{-9} \mathrm{~S} / \mathrm{cm}$, which is close to the experimental limit of the setup. We performed the fifth run in vacuum up to a maximum temperature of $597 \mathrm{~K}$ and the sixth run in synthetic air up to $612 \mathrm{~K}$ [Fig. S2(a)]. They reveal a comparable behavior to that of the third and fourth runs, respectively. During the seventh run in vacuum the sample was annealed up to $618 \mathrm{~K}$ [purple circles in Fig. 3(a)], which enhances the conductivity up to $1.7 \times 10^{-4} \mathrm{~S} / \mathrm{cm}$ (at $345 \mathrm{~K}$ ). We cooled the setup down to room temperature, filled in the synthetic air as before, and measured the conductivity several times within $3 \mathrm{~h}$ at about $345 \mathrm{~K}$ (as indicated by the green arrow). In contrast to the runs before, the conductivity remained enhanced above $3 \times 10^{-7} \mathrm{~S} / \mathrm{cm}$. During the stepwise annealing of the eighth run in synthetic air, the conductivity decreased down again close to the experimental limit, but the reoxidation was shifted to higher temperatures.

To illustrate this dependence better, we plotted the conductivity at a sample temperature of $345 \mathrm{~K}$ for all eight runs as a function of the maximum sample temperature within each run in Fig. 3(b). Like in Fig. 3(a), we indicated the flush with synthetic air into the setup between the third and fourth runs and between the seventh and eighth runs by orange and green arrows, respectively. So far, we interpret the observation by a reduction of $\alpha-\mathrm{Fe}_{2} \mathrm{O}_{3-x}$ with increasing $x$ (oxygen vacancies) that causes a higher electrical conductivity as described in the Introduction. The reoxidation in the synthetic air environment passivates the oxygen vacancies and therefore decreases the conductivity to the initial value. We note that while and directly after the synthetic air was introduced, the
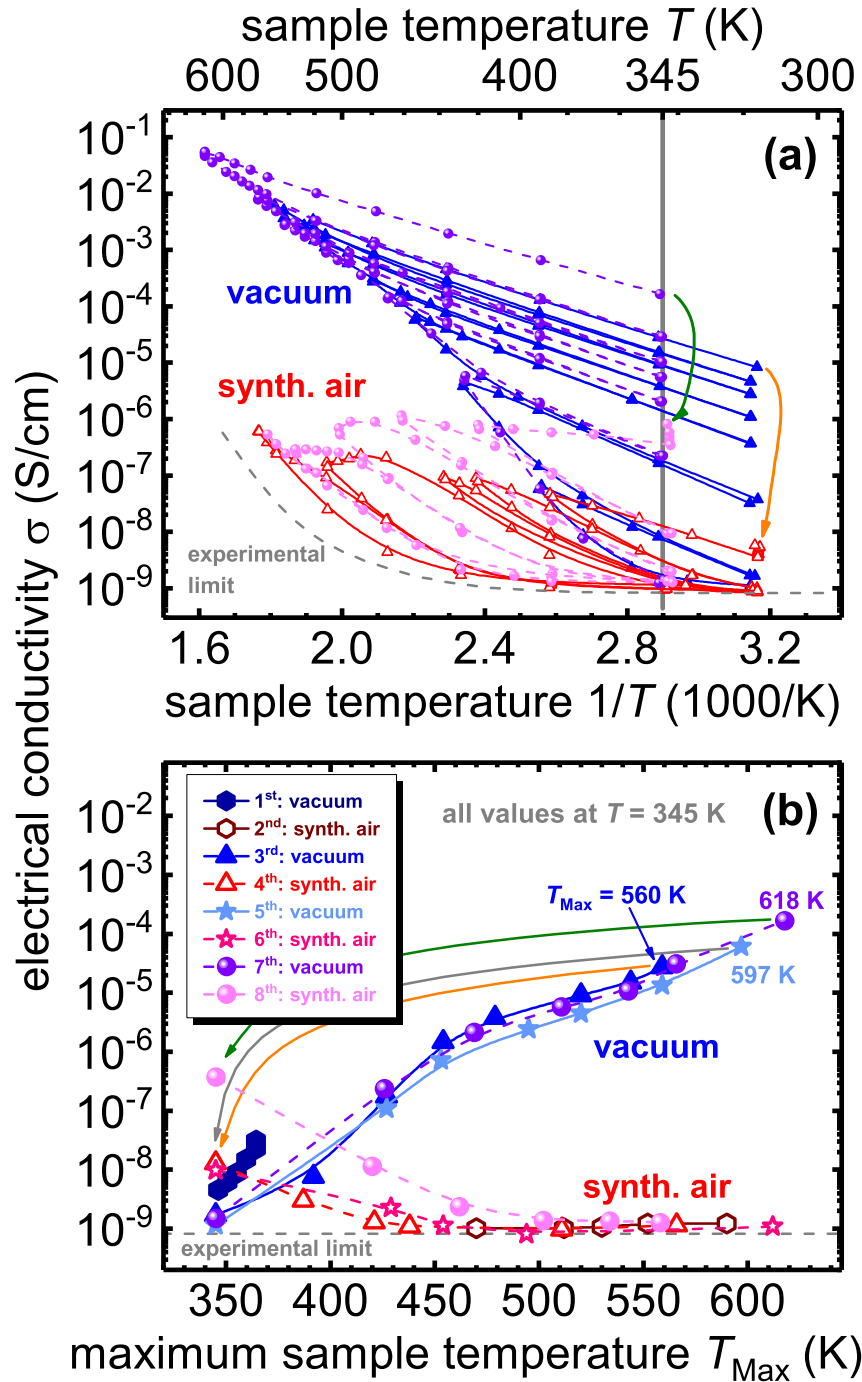

FIG. 3. Temperature-dependent electrical conductivity of a hematite nanoparticle sample with stepwise-increased maximum sample temperatures $\left(T_{\max }\right)$ [compare Fig. 1(a)] under alternating atmospheres. (a) Arrhenius plot of four of eight cycles in total are shown where the whole data set is depicted in Fig. S2(a). The third run (blue triangles) was performed at a vacuum base pressure of $\sim 1 \times 10^{-6}$ mbar up to a maximum temperature of $560 \mathrm{~K}$. Afterwards, 0.5 atm of dry synthetic air $\left(80 \% \mathrm{~N}_{2}+20 \% \mathrm{O}_{2}\right)$ was injected at room temperature in the setup and the conductivity dropped in less than 20 min by about three orders of magnitude (as indicated by the orange arrow). Successively, the fourth run was performed under synthetic air (red triangles). This procedure was repeated successively as a fifth run in vacuum up to a maximum temperature of $597 \mathrm{~K}$ and a sixth run in synthetic air [not shown in (a)]. Afterwards, the seventh run was performed in vacuum (purple circles) with $T_{\max }=618 \mathrm{~K}$ and synthetic air (magenta circles), where the synthetic air was filled in the setup at room temperature and the conductivity was measured successively at $345 \mathrm{~K}$ several times (as indicated by the green arrow). The conductivity for all eight runs at $345 \mathrm{~K}$ is plotted (b) as a function of the maximum sample temperature. As depicted in (a), the orange and green arrows indicate the conductivity drop after the flush with synthetic air. The Arrhenius plot of the first run (solid blue hexagon) is shown in Fig. S2(b), which reveals an increased conductivity for annealing above $337 \mathrm{~K}$. 


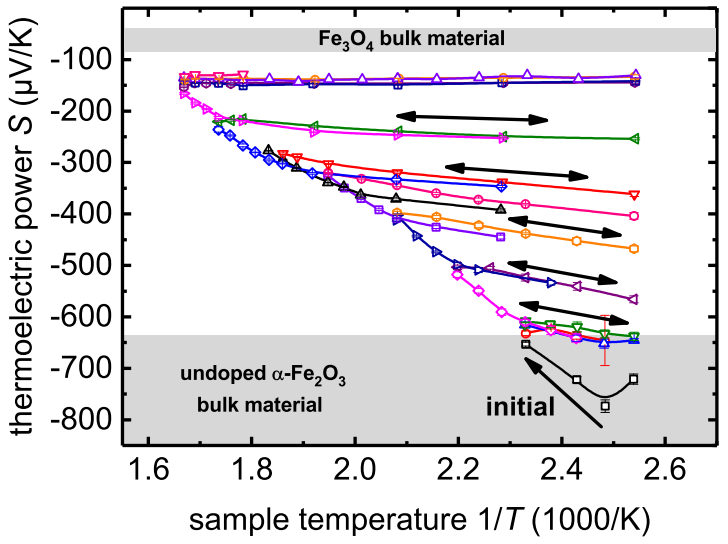

FIG. 4. Temperature-dependent thermoelectric power of a hematite nanoparticle sample for stepwise-increased maximum annealing temperature $\left(T_{\max }\right)$. Shaded regions are reference data for hematite and magnetite $[31,34,60]$. The black arrows indicate the metastable thermoelectric power levels, comparable to Fig. 1(a).

sample resistance increased within minutes over several orders of magnitude. Therefore, we assume that the conductivity enhancement is not stable under ambient conditions. For the last vacuum run (seventh run), we increased the maximum annealing temperature up to $618 \mathrm{~K}$, which causes a different behavior during the eighth reoxidation run [magenta circles in Fig. 3(b)]; i.e., the conductivity remains enhanced for maximum sample temperatures up to $500 \mathrm{~K}$ as compared to the previous two runs under air conditions. This may indicate a material change for annealing above $600 \mathrm{~K}$ in vacuum, which is more severe than the introduction of oxygen vacancies, for example, a reconstruction of the crystal lattice like a partial phase transition into magnetite $\left(\mathrm{Fe}_{3} \mathrm{O}_{4}\right)$ [45]. We consider this indication for a phase transition later.

As described in the Introduction, oxygen vacancies act as shallow donors and thus can increase the charge-carrier density of hematite. Because the electrical conductivity consists of the charge-carrier density that we attribute to the formation of $\mathrm{Fe}^{2+}$ sites caused by oxygen vacancies on the one hand, as well as the charge-carrier mobility on the other hand, we want to distinguish between the contributions of both during the annealing process. Therefore, we performed thermoelectric power measurements of nanoparticle layers as well as thin films (deposited by PECVD). The thermoelectric power of a representative nanoparticle layer sample for stepwise increased annealing temperatures is shown in Fig. 4. First, the sign of the Seebeck coefficient for all temperatures is negative, implying an $n$-type semiconductor; this identifies electrons as the dominantly contributing charge carriers. Similar to the electrical conductivity measurement in Fig. 1(a), also the thermoelectric power forms metastable levels for each maximum annealing temperature. The nanoparticle layer annealed initially at $394 \mathrm{~K}$ has a Seebeck coefficient of $-700 \mu \mathrm{V} / \mathrm{K}$ and results in a temperature-independent thermoelectric power of $-150 \mu \mathrm{V} / \mathrm{K}$ after annealing up to $600 \mathrm{~K}$. Reference values of the Seebeck coefficients of the hematite and magnetite phases of iron oxide are depicted as grey regions [31,34,60]. As explained in the Methods section in detail, we calculated the charge-carrier density with the thermoelectric power,

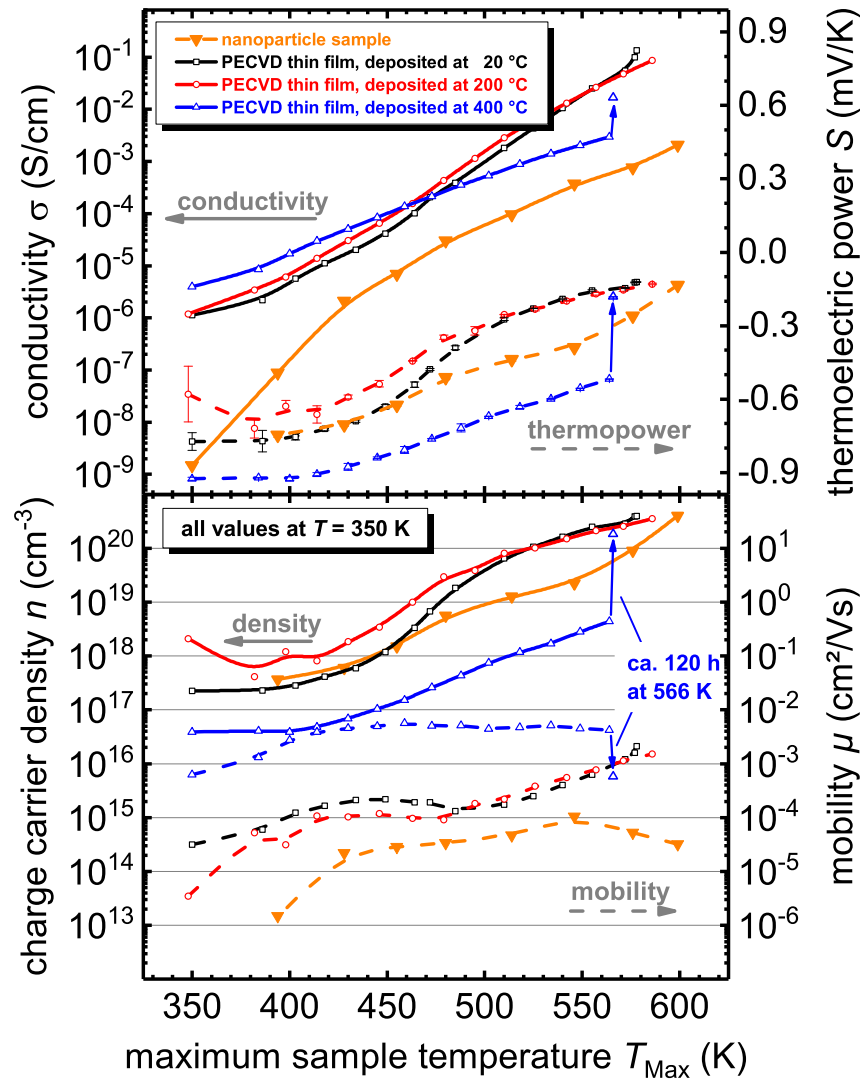

FIG. 5. Electrical conductivity, thermoelectric power, chargecarrier density, and charge-carrier mobility in dependency of the maximum annealing temperature $T_{\max }$ of a nanoparticle sample (orange) and thin-film samples prepared by PECVD with deposition temperatures of $20^{\circ} \mathrm{C}, 200^{\circ} \mathrm{C}$, and $400^{\circ} \mathrm{C}$ (depicted in black, red, and blue, respectively). All values are measured at $350 \mathrm{~K}$. The PECVD sample, which was deposited at $400^{\circ} \mathrm{C}$, was kept for about $120 \mathrm{~h}$ at $T_{\max }=566 \mathrm{~K}$ before the last data point was acquired (blue arrow).

and, by using the electrical conductivity, we determined the charge-carrier mobility.

As a summary of the transport properties, the electrical conductivity, thermoelectric power, charge-carrier density, and mobility at $350 \mathrm{~K}$ of the nanoparticle sample as well as of the thin-film samples are shown in Fig. 5 as a function of the maximum annealing temperature $T_{\max }$. As described before, the electrical conductivity increases significantly for increasing annealing temperatures; this is valid for nanoparticle layers as well as for compact PECVD thin-film layers. The PECVD samples, which were deposited at $20^{\circ} \mathrm{C}$ and $200{ }^{\circ} \mathrm{C}$, exhibit a similar behavior in conductivity and thermopower. Thereby, the sample with a deposition temperature of $400{ }^{\circ} \mathrm{C}$ differs especially in the measured thermopower, which is lowered by a constant value of roughly $300 \mu \mathrm{V} / \mathrm{K}$. This difference vanishes for the last measured point where the sample was kept at $566 \mathrm{~K}$ for about 5 days (indicated by the blue arrows). This shift in thermopower of the $400{ }^{\circ} \mathrm{C}$ sample is strongly reflected in the calculated charge-carrier density and mobility, where the last point again exhibits a comparable value to the other PECVD samples. As shown by Kaouka, the PECVD hematite film is more compact when deposited at higher substrate temperatures 


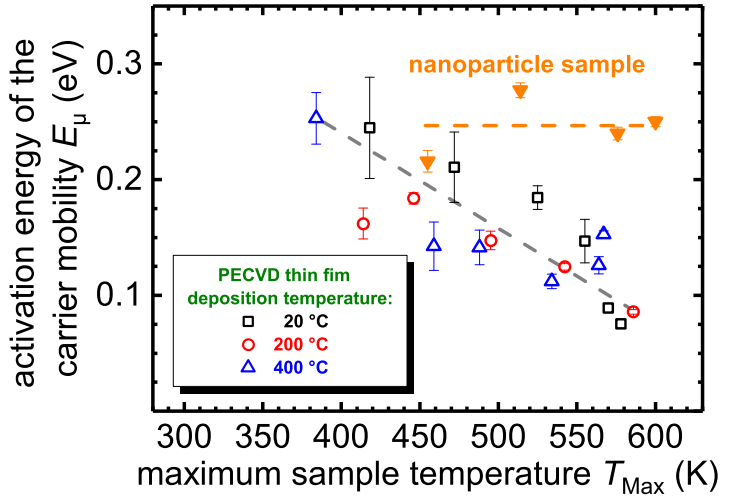

FIG. 6. Activation energy of the temperature-dependent chargecarrier mobility of a nanoparticle sample (orange) and thin-film samples prepared by PECVD with deposition temperatures of $20^{\circ} \mathrm{C}, 200^{\circ} \mathrm{C}$, and $400^{\circ} \mathrm{C}$ (depicted in black, red, and blue, respectively) as a function of $T_{\max }$. In contrast to Fig. 2, one nanoparticle sample was measured for activated mobility. An Arrhenius plot of the mobility can be found in Fig. S3.

[53]. This means that the atomic diffusion velocity is reduced in this film, which causes a significant time dependency. In addition to the annealing temperature dependence (the average duration to acquire the data for one temperature point is between 1 and $2 \mathrm{~h}$, where one data point in Fig. 5 corresponds to one annealing cycle that takes between 1 and 2 days).

Furthermore, the comparison between the charge-carrier density measured for the nanoparticle samples and those measured for the PECVD samples is very interesting. So, we state a temperature dependence of the oxygen vacancy formation that is independent of the morphology of the hematite layer, as expected in a case of thermodynamic equilibrium. In contrast, the charge-carrier mobility of the nanoparticle layer deviates for all annealing temperatures from the thin-film samples and does not exceed $1 \times 10^{-4} \mathrm{~cm}^{2} / \mathrm{V} \mathrm{s}$ (Fig. 5). Furthermore, for a wide maximum temperature range the charge-carrier mobility of the PECVD sample deposited at $400^{\circ} \mathrm{C}$ (blue triangles in Fig. 5) exhibits values about one order of magnitude higher than the PECVD samples, which are deposited at lower temperatures. Thus, in the following the charge-carrier mobility of the samples with different morphologies is discussed in more detail. Also it is worth noting that the enhanced conductivity for annealing temperatures up to $400 \mathrm{~K}$ is mainly due to an increase in charge-carrier mobility. For annealing temperatures below 400 $\mathrm{K}$ the thermopower exhibits almost constant values that result in a constant charge-carrier density.

The activation energy $E_{\mu}$ of the charge-carrier mobility as a function of the maximum annealing temperature $T_{\max }$ was determined from the Arrhenius plots of the mobility (Fig. S3 [57]) of all samples. Figure 6 demonstrates a decreasing activation energy $E_{\mu}$ of the charge-carrier mobility from $0.25 \mathrm{eV}$ down to $0.1 \mathrm{eV}$ for the PECVD samples for annealing temperatures up to $570 \mathrm{~K}$, whereby $E_{\mu}$ of the nanoparticle sample has a relatively constant value of about $0.25 \mathrm{eV}$.

The transport mechanism of charge carriers in hematite is typically described by small polaron hopping between $\mathrm{Fe}^{2+}$ and $\mathrm{Fe}^{3+}$ sites [28,61-64]. The hopping from one localized site to the next mainly depends on the lateral distance and on the influence of surrounding atoms, which can be described by a potential barrier between the sites that the electron has to overcome. This is a thermally activated phonon-assisted process in the investigated temperature region and can be considered the origin of the activated mobility $[61,62]$. Because of different iron distances in the lattice, hematite is known for highly anisotropic charge-transport properties for different crystal directions [31,65-68]. Ab initio calculation resulted in values for the potential barrier height between the initial $\mathrm{Fe}^{2+}$ state to the next $\mathrm{Fe}^{3+}$ state, in the basal plane direction, to be 0.19 or $0.29 \mathrm{eV}$ (for spin-up and spin-down states, respectively), which corresponds to a charge-carrier mobility at room temperature of $5.6 \times 10^{-4}$ and $1 \times 10^{-5} \mathrm{~cm}^{2} / \mathrm{V} \mathrm{s}$, respectively $[63,64]$. More recent modeling reported a potential barrier of $0.13 \mathrm{eV}$ that corresponds to a mobility of $9 \times 10^{-3} \mathrm{~cm}^{2} / \mathrm{V} \mathrm{s}$ [68].

These results are usually compared to prior experimental determination of an activated mobility in crystalline hematite, varying from $0.08 \mathrm{eV}$ [37] to $<0.1 \mathrm{eV}$ [66] to $0.118 \mathrm{eV}$ [69] to $0.14 \mathrm{eV}$ [31], indicating an overestimation within the calculations. Also, grain boundaries in polycrystalline hematite were considered to exhibit additional potential barriers which may hinder the electron transport and increase the activation energy up to $0.17 \mathrm{eV} \mathrm{[30].} \mathrm{But,} \mathrm{to} \mathrm{compare} \mathrm{these} \mathrm{experimental}$ values of the activated mobility with the potential barriers within the small polaron hopping model, more attention should be focused on the material properties, investigated temperature range, position of the Fermi energy (according to the Seto model for charge transport in polycrystalline semiconductors) [70] and on how these values are determined. Therefore, we gathered the reported experimental values in Table I. We want to clarify that almost all reported activated mobilities are based on highly doped hematite. The reported value of $0.08 \mathrm{eV}$ by Gharibi et al. [37] corresponds to the activation energy $E_{\mathrm{A}}$ of the conductivity (and not the activation energy $E_{\mu}$ of the mobility) of Ti-doped hematite for $T>780 \mathrm{~K}$. The reported value of $0.118 \mathrm{eV}$ by Zhao et al. [69] also corresponds to the activated conductivity of Ti-doped hematite, where the main thermal activation (shown by temperature-dependent Hall measurements in Ref. [69]) is due to an activated charge-carrier density. Therefore, within both references the activated mobility might be even smaller than reported. The value reported by Benjelloun et al. [31] $(0.14 \mathrm{eV})$ examined from (undoped) monocrystalline hematite corresponds to the difference of the activated conductivities in different crystal directions for temperatures above $1020 \mathrm{~K}$. Thus, this value is connected to the difference of the activated conductivities in the crystal directions and does not describe the absolute activated mobility for the preferred transport path. So, this value should not be considered a reference for the potential barrier height in the model of small polaron hopping. The most often referenced value reported by Goodenough $\left(E_{\mu}<0.1 \mathrm{eV}\right)$ [66] is based on the experiments of Gardner et al. [22] and Morin et al. [20], both of which were carried out with Ti-doped hematite samples and are based on the assumption that the charge-carrier density is constant for the studied temperature ranges. A comparable approach was followed by Warnes et al., who proposed a barrier height of $0.17 \mathrm{eV}$. This value is deduced from a doping series with 
TABLE I. Reported activation energies of (doped) hematite for the charge-carrier mobility $E_{\mu}$ and the conductivity $E_{\mathrm{A}}$.

\begin{tabular}{|c|c|c|c|c|}
\hline Material & Conditions & Mobility, $\mu_{\mathrm{e}}$ & Activation energy & Ref. \\
\hline$\alpha-\mathrm{Fe}_{2} \mathrm{O}_{3}$ (crystal) & $T>1020 \mathrm{~K}$ & & $E_{?}=0.14 \mathrm{eV}(?)$ & [31] \\
\hline$\alpha-\left(\mathrm{Ti}_{0.01} \mathrm{Fe}_{0.99}\right)_{2} \mathrm{O}_{3}$ & $400<T<1000 \mathrm{~K}$ & $5.6 \times 10^{-2} \mathrm{~cm}^{2} / \mathrm{V} \mathrm{s}(600 \mathrm{~K})$ & $E_{\mu}=0.1 \mathrm{eV}$ & [22] \\
\hline$\alpha-\left(\mathrm{Ti}_{0.02} \mathrm{Fe}_{0.98}\right)_{2} \mathrm{O}_{3}$ & $T>780 \mathrm{~K}$ & $2 \times 10^{-2} \mathrm{~cm}^{2} / \mathrm{V} \mathrm{s}(780 \mathrm{~K})$ & $E_{\mathrm{A}}=0.08 \mathrm{eV}$ & [37] \\
\hline$\alpha-\left(\mathrm{Ti}_{X} \mathrm{Fe}_{1-X}\right)_{2} \mathrm{O}_{3}(0.0004<X<0.007)$ & $470<T<923 \mathrm{~K}$ & $3.6 \times 10^{-1} \mathrm{~cm}^{2} / \mathrm{V} \mathrm{s}(470 \mathrm{~K})$ & $E_{\mu}=0.17 \mathrm{eV}$ & [30] \\
\hline see Ref. [22] & & & $E_{\mu}<0.1 \mathrm{eV}$ & {$[66]$} \\
\hline$\alpha-\left(\mathrm{Ti}_{0.03} \mathrm{Fe}_{0.97}\right)_{2} \mathrm{O}_{3}$ & $T=290 \mathrm{~K}$ & $4 \times 10^{-2} \mathrm{~cm}^{2} / \mathrm{V} \mathrm{s}$ & $E_{\mathrm{A}}=0.118$ & [69] \\
\hline
\end{tabular}

Ti and the assumption that the density of doping atoms and the thereby the formed amount of free charge carriers is equal. From this assumption, incorporating the electrical conductivity, the mobility was calculated and afterwards fitted to an activation energy within the hopping model. So, the underlying assumption of all doping series measurements is based on a temperature-independent charge-carrier density, which may be incorrect. Therefore, we conclude that none of the reported data might be suitable as a reference for the potential barrier height in the small polaron hopping model.

However, we want to identify the origin of the potential barrier to explain our results in the following: First, the main difference of the activated mobility within our annealed samples is between the thin films and the nanoparticle layer. It seems likely that the contact area between the nanoparticles exhibits a limiting potential barrier whose height is not affected by an increased Fermi energy. In contrast, the potential-barrier height of our polycrystalline thin films is reduced with increasing annealing temperature, which we attribute to a shift of the Fermi energy towards the conduction-band edge [70]. This indicates a different type of the limiting potential barrier within the thin-film samples. We consider the potential barriers to be at the grain boundaries and exclude the potential barrier within the polaron hopping mechanism for the following reason: The absolute value of the mobility of the PECVD thin film deposited at $400{ }^{\circ} \mathrm{C}$ is around one order of magnitude higher than the thin film deposited at lower temperatures (see Fig. 5). But the activated mobility is comparable within the uncertainties of the measurements. Thus, the potential-barrier type is the same but the absolute density of potential barriers differs. This cannot be the case if the hopping barrier would limit the charge transport. This explanation is supported by the fact that a more compact layer is formed (that corresponds to a smaller density of grain boundaries) when the film is deposited at $400{ }^{\circ} \mathrm{C}$. This is proved via electron microscopy imaging of the cross section of comparable samples [53]. However, the activation energy $E_{\mathrm{A}}$ of the electrical conductivity differs within the thin-film samples as a function of the annealing temperature as shown in Fig. 2. This difference vanishes when we plot $E_{\mathrm{A}}$ as a function of the charge-carrier density (shown in Fig. S4 [57]), which supports the hypothesis that the charge transport of all thin-film samples is limited by the same type of barrier. It is worth noting here that $E_{\mathrm{A}}$ of the nanoparticle layer plotted in Fig. S4 exhibits a steplike behavior that maybe indicates a jump of the Fermi energy which we are not able to attribute to a certain model. Furthermore, to support a future discussion, we present all activation energies as a function of the conductivity, the charge-carrier density, and mobility in the Supplemental Material (Fig. S5 [57]). However, based on the given arguments we conclude and want to clarify again that none of the presented values of the activated mobilities in this work should be considered as the potential barrier height within the polaron hopping model, which is usually applied for hematite.

In the following section, we try to distinguish between the formation of oxygen-deficient hematite $\alpha-\mathrm{Fe}_{2} \mathrm{O}_{3-x}$ and the transition into another phase of iron oxide (e.g., magnetite) in our nanoparticle films by applying Raman spectroscopy and very sensitive optical absorption spectroscopy. First, SEM is used to demonstrate the formation of a homogenous layer of the nanoparticles [see image in Fig. 7(a)]. The microscopic images before and after annealing [Figs. 7(b) and 7(c)] show that no significant change of the particle size, shape, and morphology has taken place. According to the insets in Fig. 7, which show photographs of a nanoparticle sample as deposited [Fig. 7(b)] and after annealing up to $620 \mathrm{~K}$ in vacuum [Fig. 7(c)], the color of the nanoparticle layer changed from the typical hematite orange towards a dark brown. This color change indicates a change of the material towards a stronger absorption of visible light, which was previously reported by Stone et al. for high-temperature annealed hematite powder and was interpreted as "black hematite" that consists of red particles coated with a highly conductive black layer [26,27]. Based on the work of Cornell and Schwertmann [71], the dark brown color should be considered to be magnetite $\left(\mathrm{Fe}_{3} \mathrm{O}_{4}\right)$ or maghemite $\left(\gamma-\mathrm{Fe}_{2} \mathrm{O}_{3}\right)$.

Figure 8(a) shows Raman spectra of the nanoparticle layer as deposited (red line) and after annealing in vacuum at $620 \mathrm{~K}$ (blue line). The spectrum of the as-deposited nanoparticle layer reveals Raman peaks at wave numbers of 413, 500, 612, and $662 \mathrm{~cm}^{-1}$ which can be attributed to $\alpha-\mathrm{Fe}_{2} \mathrm{O}_{3}[52,72-80]$. After annealing, two additional Raman peaks occur at 536 and $670 \mathrm{~cm}^{-1}$, which are known as Raman modes for the magnetite $\left(\mathrm{Fe}_{3} \mathrm{O}_{4}\right)$ phase of iron oxide [52,72,74,75,77,81,82]. The annealing was performed in the electrical conductivity measurement setup in vacuum as described before. Afterwards the Raman measurement was performed under ambient conditions, which verifies a stable magnetite phase at room temperature in air after annealing up to $620 \mathrm{~K}$ at a vacuum base pressure of $10^{-6}$ mbar. We also annealed a nanoparticle sample in a vacuum oven with in situ Raman spectroscopy to prevent the vacuum break. The results, shown in Fig. S6 [57], reveal no detectable phase transition at a vacuum base pressure between $10^{-2}$ and $10^{-3}$ mbar for annealing up to $823 \mathrm{~K}$.

Another approach we followed to investigate the influence of annealing under low oxygen partial pressure was to perform the annealing of the nanoparticle layer sample in a glove box under inert $\left(\mathrm{N}_{2}\right)$ atmosphere $\left(\mathrm{H}_{2} \mathrm{O}\right.$ and $\mathrm{O}_{2}<1 \mathrm{ppm}$, which 


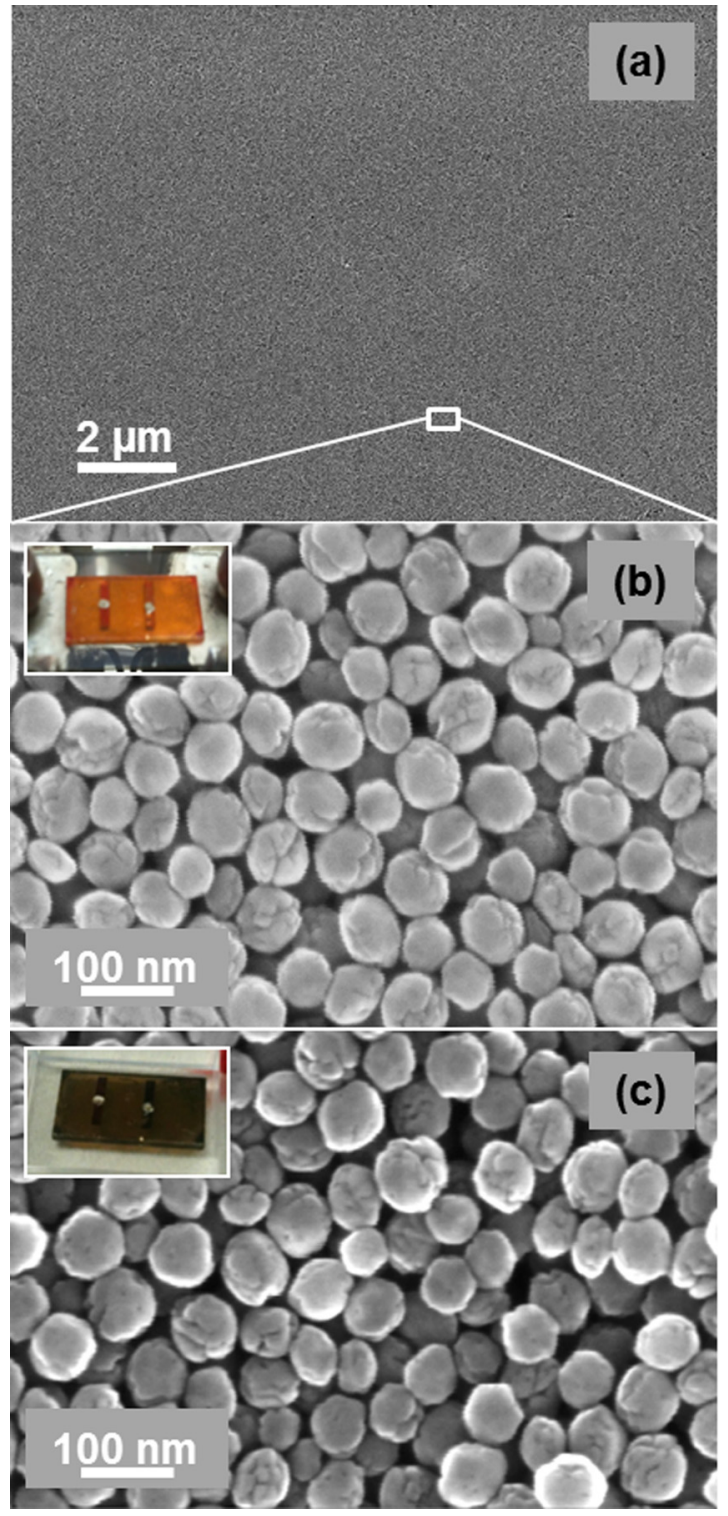

FIG. 7. Scanning electron microscopy (SEM) images of hematite nanoparticle layer (a), (b) as deposited and (c) after an annealing temperature of $620 \mathrm{~K}$ under vacuum conditions. The insets in (b) and (c) are photographs of the nanoparticle layer sample before and after annealing, respectively.

corresponds to an oxygen partial pressure that is comparable to a vacuum base pressure below $10^{-3} \mathrm{mbar}$ ). Afterwards, PDS was used to determine the optical absorptance. As described in the Methods section, the samples are transferred and measured in carbon tetrachloride $\left(\mathrm{CCl}_{4}\right)$, warranting inert conditions throughout the annealing sequence. Figure 9 shows the absorptance of the as-deposited nanoparticle layer (black line). Below $1 \mathrm{eV}$ the quartz substrate dominates the spectrum (e.g., characteristic peaks at 0.55 and $0.9 \mathrm{eV}$, labeled by *). Between 1 and $2 \mathrm{eV}$ the absorptance increases, showing a peak at about $1.4 \mathrm{eV}$ (label A) and a shoulder at $1.9 \mathrm{eV}$ (label B) that can be attributed to the characteristic transition of the $\mathrm{Fe}^{3+}$ $d$ electrons [83-88]. Above $2.1 \mathrm{eV}$ the band-gap absorption takes place. A significant enhancement of the sub-band-gap

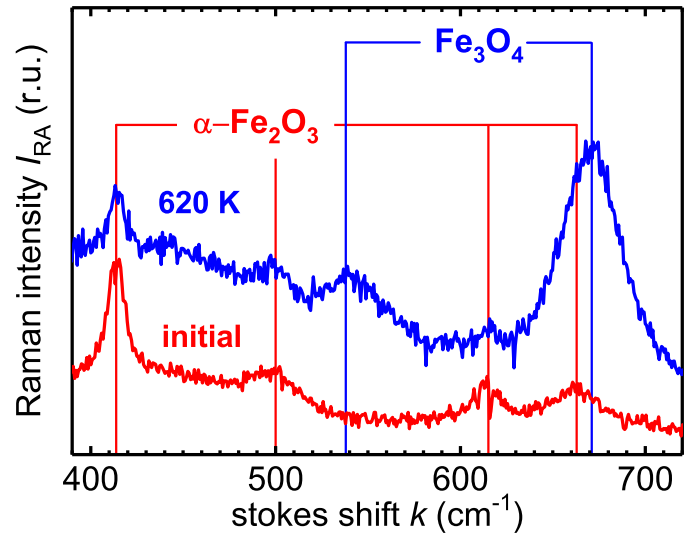

FIG. 8. Raman spectroscopy measurements at room temperature of nanoparticle samples. As deposited (red) and after annealing up to $620 \mathrm{~K}$ at a vacuum base pressure of $\sim 1 \times 10^{-6} \mathrm{mbar}$ (blue). Raman modes of $\alpha-\mathrm{Fe}_{2} \mathrm{O}_{3}$ and $\mathrm{Fe}_{3} \mathrm{O}_{4}$ are indicated by the red and blue vertical lines, respectively [52,72-82].

absorption was observed for an annealing temperature of $473 \mathrm{~K}$ (red line), which increased even further with higher annealing temperatures up to $573 \mathrm{~K}$. In principle this increase could be due to additional absorption of magnetite or sub-band-gap (defect) absorption of hematite. We excluded the formation of magnetite as a separate phase by calculating the absorptance of several combinations of hematite with a small content of magnetite in Fig. S7 [57,89]. Therefore, we interpret the enhanced sub-band-gap absorption with rising annealing temperatures to be caused by a rising defect density (i.e., oxygen vacancies or iron interstitials).

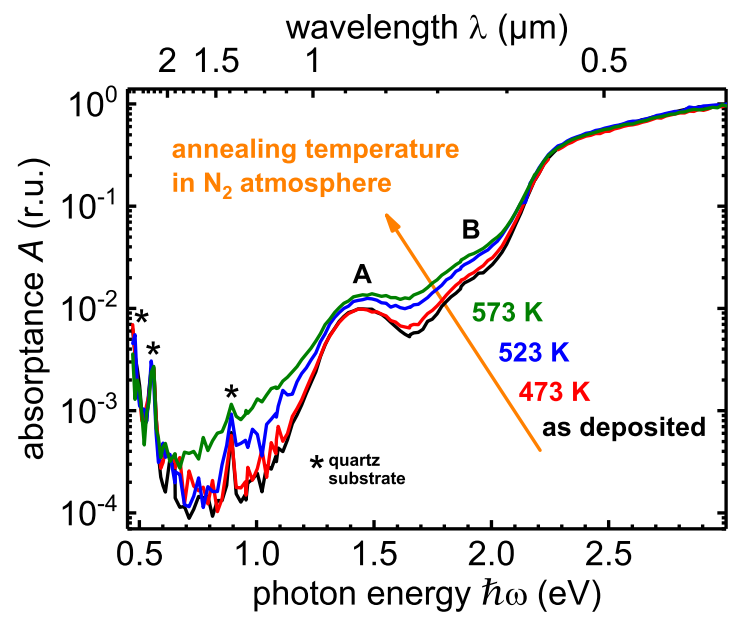

FIG. 9. Photothermal deflection spectroscopy (PDS) of a nanoparticle layer sample, which was stepwise annealed under inert $\left(\mathrm{N}_{2}\right)$ atmosphere. An increased sub-band-gap absorption is detected for annealing temperatures of $473 \mathrm{~K}$ and increases further with rising annealing temperature. This increased absorption can be due to defect absorption in oxygen-deficient hematite $\left(\alpha-\mathrm{Fe}_{2} \mathrm{O}_{3-x}\right.$ with rising $x$ ). Below $1 \mathrm{eV}$ the quartz substrate dominates the spectrum (e.g., characteristic peaks at 0.9 and $0.55 \mathrm{eV}$, labeled by *). Labels A and $\mathrm{B}$ mark the absorption of the characteristic transition of $\mathrm{Fe}^{3+} d$ electrons at 1.4 and $1.9 \mathrm{eV}$, respectively. 
Now, we want to combine the results of the electrical transport and the spectroscopic measurements. We found a continuously enhanced electrical conductivity of hematite during vacuum annealing that is mainly due to an increased charge-carrier density which we attribute to the formation of oxygen vacancies that cause $\mathrm{Fe}^{2+}$ sites. This observation is valid for nanoparticle layers as well as for thin-film samples. After an annealing up to $620 \mathrm{~K}$ at a vacuum base pressure of $1 \times 10^{-6}$ mbar, we identified Raman modes of the magnetite phase (at a vacuum base pressure of $1 \times 10^{-2} \mathrm{mbar}$, no phase transition was detectable for annealing up to $823 \mathrm{~K}$ ). So the question arises, at which temperature between $337 \mathrm{~K}$ (where the first detectable enhancement of the electrical conductivity occurs) and $620 \mathrm{~K}$ (where the magnetite phase is detected) does the reconstruction of the crystal lattice from the hematite corundum-type structure towards the magnetite spinel-type structure take place $[34,45,49]$ ? The electrical conductivity measurements under alternating atmospheres revealed a higher reoxidation temperature for reduced nanoparticle layers if they were annealed above $600 \mathrm{~K}$. This may indicate a reorganization of the crystal lattice that is more severe than the formation of oxygen vacancies that causes a higher reoxidation temperature. Considering the electrical bulk properties of magnetite [90], a hypothetical formation of a homogenous magnetite film with a thickness of $1 \mathrm{~nm}$ on top of a 500-nm hematite film would already enhance the effective conductivity from about $1 \times 10^{-13} \mathrm{~S} / \mathrm{cm}$ [20] up to $0.4 \mathrm{~S} / \mathrm{cm}$ (at $300 \mathrm{~K}$ ). This approximation is of course inappropriate for a layer of nanoparticles, but it demonstrates the huge discrepancy between the conductivity of hematite and magnetite. However, the model of a percolation transport through a discrete second phase would predict a discontinuity of transport properties (percolation edge). However, the continuous change of the electrical conductivity, the activation energy, and the thermoelectric power negate this explanation. The formation of native point defects under reducing conditions while annealing is supported by an increased sub-band-gap absorption measured by PDS. Thus, we deduce from our observations that the phase-transition temperature is between 600 and $620 \mathrm{~K}$ (at a vacuum base pressure of $1 \times 10^{-6} \mathrm{mbar}$ ).

However, this observation is in contradiction to the expected phase-change transition temperature of more than $1000 \mathrm{~K}$ for an oxygen partial pressure of $1 \times 10^{-7}$ mbar [49]. Furthermore, it is in contradiction to low-energy electron diffraction (LEED) crystallography studies of single-crystal hematite that confirmed the surface reconstruction of hematite into magnetite for temperatures above $900 \mathrm{~K}$ at $1 \times 10^{-6} \mathrm{mbar}$ oxygen partial pressure [91,92]. However, Rioult et al. reported recently, based on x-ray photoelectron spectroscopy (XPS) measurements of thin-film hematite, a detectable crystallographic change for annealing above $673 \mathrm{~K}$ at about $1 \times$ $10^{-9}$ mbar (UHV) that was attributed to a very small amount of magnetite (spinel-type) structure, where the majority of the material was still in the hematite (corundum-type) structure.

Therefore, we interpret the continuously enhanced conductivity as an increased doping by oxygen vacancies (or iron interstitials) in hematite for temperatures above $337 \mathrm{~K}$. But the introduced charge carriers are not directly detectable for annealing temperatures up to $400 \mathrm{~K}$, where the enhanced conductivity is due to an enhanced charge-carrier mobility.
But, as described before, we state that potential barriers at the grain boundaries or at the internanoparticle contact areas limit the charge transport. So, if we assume a high defect density at those barriers, it is imaginable that also for temperatures below $400 \mathrm{~K}$ oxygen vacancies are introduced. But the thereby delocalized charge carriers are localized (trapped) at those barriers, which lowers the potential-barrier height and increases the charge-carrier mobility (according to the Seto model) [70].

As described in the Introduction, a reducing atmosphere during sample preparation enhances the electrical conductivity of hematite. Due to the reversibility of the electrical conductivity enhancement by using dry synthetic air, as shown in Fig. 3, we confirmed that the conductivity change is strongly correlated to the oxygen content of the iron oxide phase.

As stated by the pioneer work of Bevan et al. [18], we demonstrated that electrical conductivity as well as thermoelectric power measurements are highly sensitive to the formation of oxygen-deficient hematite, which is a useful addition towards a detailed understanding of the concept of native defect doping to improve the electrical properties of hematite. In addition, the results provide valuable data to estimate the stability of devices or films based on hematite at elevated temperatures.

\section{CONCLUSION}

In this work we performed a detailed study on the enhanced transport properties of hematite $\left(\alpha-\mathrm{Fe}_{2} \mathrm{O}_{3}\right)$ nanoparticle layers as well as thin films during moderate annealing (300-620 K) under reducing atmosphere. This method is a promising approach for native defect doping which gets applied for hematite photoanodes in water-splitting devices [38-47]. We demonstrated an increased electrical conductivity of more than five orders of magnitude. By thermoelectric power measurements we were able to attribute this enhancement to an increased charge-carrier density of more than three orders of magnitude and increased charge-carrier mobility by around 1.5 orders of magnitude. We verified the reversibility of this effect by repeating the measurements in vacuum and synthetic air and therefore demonstrated the origin of the charge carriers to be from oxygen vacancies which act as shallow donors. By Raman spectroscopy measurements we identified the magnetite $\left(\mathrm{Fe}_{3} \mathrm{O}_{4}\right)$ phase of iron oxide after annealing up to $620 \mathrm{~K}$ at a vacuum base pressure of about $1 \times 10^{-6} \mathrm{mbar}$. Therefore, we discussed the transition of the oxygen-deficient hematite $\left(\alpha-\mathrm{Fe}_{2} \mathrm{O}_{3-x}\right.$ with increasing $\left.x\right)$ towards $\mathrm{Fe}_{3} \mathrm{O}_{4}$.

\section{ACKNOWLEDGMENTS}

This work was partially funded by the German Federal Ministery of Education and Research (BMBF) Project No. 03SF0402A, "NADNuM." The authors would like to thank Dr. Karla Dörmbach of the Institute of Interactive Materials Research DWI an der RWTH Aachen e.V. for providing the hematite nanoparticles as well as Ali Kaouka (and the group of Professor Mathur, University of Cologne) for providing the PECVD thin films. Furthermore, we want to thank Oliver Thimm and Josef Klomfaß (FZJ) for the PDS measurements and Markus Hülsbeck (FZJ) for kind support with the Raman spectroscopy. 
[1] K. Sivula, F. Le Formal, and M. Grätzel, ChemSusChem 4, 432 (2011)

[2] M. J. Katz, S. C. Riha, N. C. Jeong, A. B. F. Martinson, O. K. Farha, and J. T. Hupp, Coord. Chem. Rev. 256, 2521 (2012).

[3] S. Shen, S. A. Lindley, X. Chen, and J. Z. Zhang, Energy Environ. Sci. 9, 2744 (2016).

[4] Gurudayal, D. Sabba, M. H. Kumar, L. H. Wong, J. Barber, M. Grätzel, and N. Mathews, Nano Lett. 15, 3833 (2015).

[5] N. V. Long, T. Teranishi, Y. Yang, C. M. Thi, Y. Cao, and M. Nogami, Int. J. Metall. Mater. Eng. 1, 119 (2015).

[6] A. Gurlo and R. Riedel, Angew. Chem. Int. Ed. 46, 3826 (2007).

[7] A. D. Arulsamy, K. Eleršič, M. Modic, U. Cvelbar, and M. Mozetič, ChemPhysChem 11, 3704 (2010).

[8] F. Rettig and R. Moos, Sens. Actuators B Chem. 145, 685 (2010).

[9] C. Wu, P. Yin, X. Zhu, C. OuYang, and Y. Xie, J. Phys. Chem. B 110, 17806 (2006).

[10] L.-S. Zhong, J.-S. Hu, H.-P. Liang, A.-M. Cao, W.-G. Song, and L.-J. Wan, Adv. Mater. 18, 2426 (2006).

[11] X.-L. Fang, C. Chen, M.-S. Jin, Q. Kuang, Z.-X. Xie, S.-Y. Xie, R.-B. Huang, and L.-S. Zheng, J. Mater. Chem. 19, 6154 (2009).

[12] Y. Lin, G. Yuan, S. Sheehan, S. Zhou, and D. Wang, Energy Environ. Sci. 4, 4862 (2011).

[13] A. G. Tamirat, J. Rick, A. A. Dubale, W.-N. Su, and B.-J. Hwang, Nanoscale Horiz. 1, 243 (2016).

[14] D. A. Wheeler, G. Wang, Y. Ling, Y. Li, and J. Z. Zhang, Energy Environ. Sci. 5, 6682 (2012).

[15] A. B. Murphy, P. R. F. Barnes, L. K. Randeniya, I. C. Plumb, I. E. Grey, M. D. Horne, and J. A. Glasscock, Int. J. Hydrogen Energy 31, 1999 (2006).

[16] M. P. Dare-Edwards, J. B. Goodenough, A. Hamnett, and P. R. Trevellick, J. Chem. Soc., Faraday Trans. 1 79, 2027 (1983).

[17] C. Wagner and E. Koch, Z. Phys. Chem., Abt. B 32(6), 439 (1936).

[18] D. J. M. Bevan, J. P. Shelton, and J. S. Anderson, J. Chem. Soc. (Resumed) 0, 1729 (1948).

[19] F. Morin, Phys. Rev. 83, 1005 (1951).

[20] F. Morin, Phys. Rev. 93, 1195 (1954).

[21] D. S. Tannhauser, J. Phys. Chem. Solids 23, 25 (1962).

[22] R. Gardner, F. Sweett, and D. Tanner, J. Phys. Chem. Solids 24, 1175 (1963).

[23] R. Gardner, F. Sweett, and D. Tanner, J. Phys. Chem. Solids 24, 1183 (1963).

[24] D. Tanner, F. Sweett, and R. Gardner, Br. J. Appl. Phys. 15, 1041 (1964).

[25] H. Van Daal and A. Bosman, Phys. Rev. 158, 736 (1967).

[26] H. E. N. Stone and B. L. Daniell, J. Mater. Sci. 2, 307 (1967).

[27] H. E. N. Stone, J. Mater. Sci. 3, 321 (1968).

[28] A. Bosman and H. Van Daal, Adv. Phys. 19, 1 (1970).

[29] R. Chang and J. Wagner, J. Am. Ceram. Soc. 55, 211 (1972).

[30] B. Warnes, F. Aplan, and G. Simkovich, Solid State Ionics 12, 271 (1984).

[31] D. Benjelloun, J.-P. Bonnet, J.-P. Doumerc, J.-C. Launay, M. Onillon, and P. Hagenmuller, Mater. Chem. Phys. 10, 503 (1984).

[32] C. Gleitzer, J. Nowotny, and M. Rekas, Appl. Phys. A 53, 310 (1991).

[33] R. Dieckmann, Philos. Mag. A 68, 725 (1993).

[34] C. Gleitzer, Key Eng. Mater. 125, 355 (1997).
[35] S. Kment, Z. Hubicka, J. Krysa, J. Olejnicek, M. Cada, I. Gregora, M. Zlamal, M. Brunclikova, Z. Remes, N. Liu et al., Catal. Today 230, 8 (2014).

[36] K. D. Malviya, H. Dotan, D. Shlenkevich, A. Tsyganok, H. Mor, and A. Rothschild, J. Mater. Chem. A 4, 3091 (2016).

[37] E. Gharibi, A. Hbika, B. Dupre, and C. Gleitzer, Eur. J. Solid State Inorg. Chem. 27, 647 (1990).

[38] Y. Ling, G. Wang, J. Reddy, C. Wang, J. Z. Zhang, and Y. Li, Angew. Chem. Int. Ed. 51, 4074 (2012).

[39] G. Wang, Y. Ling, and Y. Li, Nanoscale 4, 6682 (2012).

[40] A. Pu, J. Deng, M. Li, J. Gao, H. Zhang, Y. Hao, J. Zhong, and X. Sun, J. Mater. Chem. A 2, 2491 (2014).

[41] J. Engel, Ph.D. dissertation, Massachusetts Institute of Technology, 2014.

[42] J. Engel and H. L. Tuller, Phys. Chem. Chem. Phys. 16, 11374 (2014).

[43] A. Mettenbörger, T. Singh, A. P. Singh, T. T. Järvi, M. Moseler, M. Valldor, and S. Mathur, Int. J. Hydrogen Energy 39, 4828 (2014).

[44] Q. Yu, X. Meng, L. Shi, G. Liu, P. Li, and J. Ye, RSC Adv. 6, 62263 (2016).

[45] M. Rioult, D. Stanescu, E. Fonda, A. Barbier, and H. Magnan, J. Phys. Chem. C 120, 7482 (2016).

[46] M. Li, J. Deng, A. Pu, P. Zhang, H. Zhang, J. Gao, Y. Hao, J. Zhong, and X. Sun, J. Mater. Chem. A 2, 6727 (2014).

[47] T.-Y. Yang, H.-Y. Kang, U. Sim, Y.-J. Lee, J.-H. Lee, B. Koo, K. T. Nam, and Y.-C. Joo, Phys. Chem. Chem. Phys. 15, 2117 (2013).

[48] X. Zhao, J. Feng, S. Chen, Y. Huang, T. C. Sum, and Z. Chen, Phys. Chem. Chem. Phys. 19, 1074 (2017).

[49] G. Ketteler, W. Weiss, W. Ranke, and R. Schlögl, Phys. Chem. Chem. Phys. 3, 1114 (2001).

[50] M. Ozaki, S. Kratohvil, and E. Matijević, J. Colloid Interface Sci. 102, 146 (1984).

[51] K. Doermbach, G. Agrawal, M. Servos, S. Schipmann, S. Thies, U. Klemradt, and A. Pich, Part. Part. Syst. Charact. 31, 365 (2014).

[52] M. Nuys, Dissertation, Rheinisch-Westfälischen Technischen Hochschule Aachen, 2015.

[53] A. Kaouka, Dissertation, Universität zu Köln, 2016.

[54] A. P. Singh, A. Mettenbörger, P. Golus, and S. Mathur, Int. J. Hydrogen Energy 37, 13983 (2012).

[55] W. Beyer and H. Overhof, in Hydrogenated Amorphous Silicon Electronic and Transport Properties, Semiconductors and Semimetals, edited by J. I. Pankove (Elsevier, Amsterdam, 1984), Vol. 21, Chap. 8, pp. 257-307.

[56] C. Sellmer, Dissertation, Rheinisch-Westfälischen Technischen Hochschule Aachen, 2011.

[57] See Supplemental Material at http://link.aps.org/supplemental/ 10.1103/PhysRevMaterials.1.065407 for more information on experimental setup; alternative calculation based on the assumption of dominant phonon scattering in Eq. (3); complete dataset of Fig 3; Arrhenius plots required for activation energies shown in Fig. 6; activated conductivity as a function of the carrier density; additional Raman spectroscopy measurements; calculated absorption spectra of hematite with small amounts of magnetite.

[58] A. C. Boccara, D. Fournier, W. Jackson, and N. M. Amer, Opt. Lett. 5, 377 (1980). 
[59] W. B. Jackson, N. M. Amer, A. C. Boccara, and D. Fournier, Appl. Opt. 20, 1333 (1981).

[60] H. Graener, M. Rosenberg, T. E. Whall, and M. R. B. Jones, Philos. Mag. Part B 40, 389 (1979).

[61] J. Appel, in Solid State Physics, edited by F. Seitz, H. Ehrenreich, and D. Turnbull (Academic Press, New York, 1968), pp. 193-391.

[62] I. Austin and N. F. Mott, Adv. Phys. 18, 41 (1969).

[63] K. M. Rosso, D. M. Smith, and M. Dupuis, J. Chem. Phys. 118, 6455 (2003).

[64] N. Iordanova, M. Dupuis, and K. M. Rosso, J. Chem. Phys. 122, 144305 (2005).

[65] T. Nakau, J. Phys. Soc. Jpn. 15, 727 (1960).

[66] J. B. Goodenough, Prog. Solid State Chem. 5, 145 (1971).

[67] C. M. Eggleston, A. J. A. Shankle, A. J. Moyer, I. Cesar, and M. Grätzel, Aquat. Sci. 71, 151 (2009).

[68] N. Adelstein, J. B. Neaton, M. Asta, and L. C. De Jonghe, Phys. Rev. B 89, 245115 (2014).

[69] B. Zhao, T. C. Kaspar, T. C. Droubay, J. McCloy, M. E. Bowden, V. Shutthanandan, S. M. Heald, and S. A. Chambers, Phys. Rev. B 84, 245325 (2011).

[70] J. Y. W. Seto, J. Appl. Phys. 46, 5247 (1975).

[71] R. M. Cornell and U. Schwertmann, The Iron Oxides: Structure, Properties, Reactions, Occurrences and Uses (John Wiley \& Sons, New York, 2006).

[72] M. Hanesch, Geophys. J. Int. 177, 941 (2009).

[73] I. R. Beattie and T. R. Gilson, J. Chem. Soc. A: Inorg. Phys. Theor. 0, 980 (1970).

[74] S. J. Oh, D. C. Cook, and H. E. Townsend, Hyperfine Interact. 112, 59 (1998).

[75] D. L. A. De Faria, S. Venâncio Silva, and M. T. De Oliveira, J. Raman Spectrosc. 28, 873 (1997).
[76] C. G. Shull, W. A. Strauser, and E. O. Wollan, Phys. Rev. 83, 333 (1951).

[77] T. R. Hart, H. Temkin, and S. B. Adams, Light scattering in magnetite, $\mathrm{Fe} 3 \mathrm{O} 4$, in Proceedings of the 4th International Conference on Light Scattering Solids, 3rd (Wiley, New York, 1976), pp. 254-258.

[78] T. P. Martin, R. Merlin, D. R. Huffman, and M. Cardona, Solid State Commun. 22, 565 (1977).

[79] K. F. McCarty, Solid State Commun. 68, 799 (1988).

[80] M. J. Massey, U. Baier, R. Merlin, and W. H. Weber, Phys. Rev. B 41, 7822 (1990).

[81] O. N. Shebanova and P. Lazor, J. Raman Spectrosc. 34, 845 (2003).

[82] J. Dünnwald and A. Otto, Fresenius Z. Anal. Chem. 319, 738 (1984).

[83] P. Merchant, R. Collins, R. Kershaw, K. Dwight, and A. Wold, J. Solid State Chem. 27, 307 (1979).

[84] G. Horowitz, J. Electroanal. Chem. Interfacial Electrochem. 159, 421 (1983).

[85] D. M. Sherman, Phys. Chem. Miner. 12, 161 (1985).

[86] D. M. Sherman and T. D. Waite, Am. Mineral. 70, 1262 (1985).

[87] S. M. Ahmed, J. Leduc, and S. F. Haller, J. Phys. Chem. 92, 6655 (1988).

[88] S. P. Tandon and J. P. Gupta, Spectrosc. Lett. 3, 297 (1970).

[89] P. Muret, Solid State Commun. 14, 1119 (1974).

[90] P. A. Miles, W. B. Westphal, and A. Von Hippel, Rev. Mod. Phys. 29, 279 (1957).

[91] W. Weiss, A. Barbieri, M. A. Van Hove, and G. A. Somorjai, Phys. Rev. Lett. 71, 1848 (1993).

[92] A. Barbieri, W. Weiss, M. Van Hove, and G. Somorjai, Surf. Sci. 302, 259 (1994). 